\title{
Dynamic Study on Tourism Carbon Footprint and Carbon Carrying Capacity in Sichuan Province
}

\author{
Yu Ren, Chunrong Zhao, Juanlin Fu \\ School of Civil Engineering and Architecture, Southwest University of Science and Technology, Mianyang, China \\ Email: 1545202906@qq.com
}

How to cite this paper: Ren, Y., Zhao, C. R., \& Fu, J. L. (2019). Dynamic Study on Tourism Carbon Footprint and Carbon Carrying Capacity in Sichuan Province. Journal of Geoscience and Environment Protection, 7, 14-24.

https://doi.org/10.4236/gep.2019.77002

Received: May 29, 2019

Accepted: July 15, 2019

Published: July 18, 2019

Copyright ( 2019 by author(s) and Scientific Research Publishing Inc. This work is licensed under the Creative Commons Attribution International License (CC BY 4.0).

http://creativecommons.org/licenses/by/4.0/

\section{(c) (i) Open Access}

\begin{abstract}
Tourism carbon emission is one of the important factors affecting ecological environment. In order to clarify the trend and changing characteristics of tourism carbon emissions, academia has carried out quantitative research on tourism carbon footprint. Based on the theory of carbon footprint, this study analyzes the tourism carbon emissions in Sichuan Province from 2004 to 2018 through three indexes: tourism carbon footprint, carbon carrying capacity and net carbon footprint. The results show that the carbon footprint of tourism in Sichuan Province shows an increasing trend. During the fifteen years, it increases by 20.2 times from 427.59 million tons to 9505.95 million tons. The carbon carrying capacity of tourism is increasing year by year except in 2008. Sichuan Province was in a carbon surplus before 2012. The carbon carrying capacity is greater than the carbon footprint, which is friendly to the ecological environment. After 2012, Sichuan Province is in a state of carbon deficit, and the ecological pressure is increasing, which is not conducive to human survival.
\end{abstract}

\section{Keywords}

Tourism Carbon Footprint, Tourism Carbon Carrying Capacity, Net Carbon Footprint, Tourism, Sichuan Province

\section{Introduction}

Tourism is one of the fastest growing industrial sectors in the world, and it is also a sector with more carbon emissions in the senior industry. However, human tourism produces about 5 percent of the world's carbon emissions, which has a great impact on global warming (Scott et al., 2008). In view of such ecological and environmental problems, scholars at domestic and abroad have carried out a 
series of research from the perspective of tourism carbon footprint. We know that the concept of carbon footprint can be divided into two categories in many documents. The first is to lead the tourism carbon footprint on the basis of the ecological footprint, that is to combine the bearing capacity. It refers to the area of ecological bearing capacity required to absorb greenhouse gases such as carbon dioxide generated by tourism activities. The other is based on the amount of greenhouse gas emitted by tourists undefined tourism activities (Lu, 2018; Weidema et al., 2008).

In terms of research content, it considers the tourism sub-department. Based on the construction of tourism carbon footprint model, Yao Guo et al., a domestic scholar, analyzed the tourism carbon footprint in Hunan Province. It is concluded that the proportion of carbon footprint of tourism transportation is the highest, followed by tourism accommodation, and the proportion of tourism activities is the lowest. It indicates that tourism transportation contributes the most to tourism carbon footprint (Yao \& Chen, 2016). Zhuo Wu used life cycle assessment theory and input-output theory to measure the carbon footprint of Nanyue tourists in catering, accommodation, transportation and tourism activities. The results showed that the carbon footprint of tourism and transportation accounted for $56.1 \%$, which was the most. The carbon footprint of tourism accommodation and tourism activities is second, and tourism and catering have the least carbon footprint ( $\mathrm{Wu}, 2015)$. Donghui Jiang and others calculated the carbon footprint of tourism and the six sectors of tourism in 2013 by building a model to calculate the carbon footprint of tourism in Shandong Province. Finally, he proposed that the main direction of tourism energy saving and emission reduction in Shandong Province is to reduce the carbon footprint of tourism traffic (Jiang \& Jin, 2015).

For the research on the measurement of tourism carbon footprint, scholars at domestic and abroad think that there are two methods: top-down and bottom-up. The former is carried out from top to bottom by using statistical data of energy consumption at the national level. The latter uses survey data from the perspective of carbon footprint to carry out statistics from the bottom up (Zhao et al., 2014). Wang Kai et al. used the bottom-up calculation method to analyze the total $\mathrm{CO}_{2}$ emissions, tourism receptions and per capita tourism income in each region from a dynamic perspective. The changing trend characteristics of influencing factors such as $\mathrm{CO}_{2}$ emission intensity and $\mathrm{CO}_{2}$ emission ratio of tourism traffic (Wang et al., 2017). Becken et al. used a top-down and bottom-up approach to account for tourism carbon footprint in New Zealand. It shows that different tourism choices in the transport, accommodation, attractiveness and activity subsectors require different amounts of energy and how to make up the total energy bill for international and domestic tourists in New Zealand. The results show that traffic occupies a dominant position and its contribution to international and domestic tourists is $65 \%$ and $73 \%$ respectively, which is the core of energy saving measures (Becken et al., 2003). Gossling et al. used a bottom-up approach to estimate emissions from tourism in Sweden. The results showed 
that these emissions accounted for about 10\% of Sweden's emissions and increased rapidly (Gössling \& Michael, 2008).

To sum up, the research on carbon footprint at domestic and abroad involves different aspects. However, there are relatively few discussions in the field of carbon bearing capacity. Therefore, the dynamic changes of carbon footprint and carbon bearing capacity in Sichuan Province in the past 15 years are analyzed in this paper. It grasps the influence degree of tourism carbon footprint on ecological environment in Sichuan Province, and provides the basis for the government to formulate carbon emission reduction measures in the future.

\section{Calculation Model of Tourism Carbon Footprint}

\subsection{Tourism Carbon Footprint Model}

Carbon footprint refers to the total amount of climate change-related gases emitted in human production and consumption activities. It is a process of analyzing the carbon emission directly and indirectly related to the product life cycle from the perspective of life cycle (Liao \& Gong, 2014). The carbon footprint comes from the ecological footprint, and the tourism carbon footprint is the extension of the carbon footprint. It brings tourism into the study of carbon footprint and analyzes the impact of greenhouse gases produced by tourists undefined consumption on the environment in the process of tourism. In this way, the carbon footprint can be viewed from the perspective of tourism and the basis can be provided for the tourism industry to put forward carbon emission reduction measures. The basic formula for tourism carbon footprint is as follows (Dong et al., 2018):

$$
\begin{gathered}
\mathrm{TCF}=E \times G \\
\overline{\mathrm{TCF}}=\mathrm{TCF} \div N
\end{gathered}
$$

In the formula: TCF is the total carbon footprint of tourism, unit: $t, E$ is the total revenue of the tourism industry, unit: dollar; $G$ is the comprehensive carbon dioxide emission intensity of tourism industry, unit: $\mathrm{kg} /$ thousand dollars; $\overline{\mathrm{TCF}}$ is the per capita carbon footprint of tourism, unit: $\mathrm{kg} /$ person; $N$ is the number of regional tourists within a year. According to the research results of Cao Hui (Cao et al., 2014), Liguo Wang (Wang et al., 2011) and Hongyan Dong (Dong et al., 2018), the world average carbon emission intensity of tourism is adopted as the reference value of $G$ in this paper.

\subsection{Tourism Carbon Capacity Model}

Carbon carrying capacity refers to the amount of fixed $\mathrm{CO}_{2}$ absorbed by various vegetations in an area every year (Zhao et al., 2013a). Woodland is the largest carbon sink and accounts for more than $96 \%$ of the total carbon sink in Sichuan province. Therefore, the carbon sequestration of forests is only calculated in this paper. The calculation method is combined with the method of Xiangui Zhao (Zhao et al., 2013b), Hongyan Dong (Dong et al., 2018). The calculation formula is as follows: 


$$
\begin{aligned}
\mathrm{CC}=N \times \mathrm{cc} & =S \times \mathrm{CNEP} \times 44 \div 12 \\
\mathrm{TCC} & =\mathrm{CC} \times r \\
\overline{\mathrm{TCC}} & =\mathrm{TCF} \div N
\end{aligned}
$$

In the formula: $C C$ is the region's carbon carrying capacity, unit: $\mathrm{kt}$; $c c$ is the per capita carbon carrying capacity, unit: ton/person; $S$ is the area of forest, unit: $\mathrm{hm}^{2} ; C_{N E P}$ is the amount of carbon absorbed by $1 \mathrm{hm}^{2}$ vegetation in one year, unit: $\mathrm{t} \times \mathrm{hm}^{-2} \times \mathrm{a}^{-1}$. The value of net ecosystem productivity (NEP) is not uniform, so the net ecosystem productivity NEP of Sichuan province is set as 3.809592 according to the carbon absorption coefficient of main productive land sorted out by Peng et al. (2016). TCC is the tourism carbon carrying capacity, and $r$ is the tourism carbon carrying capacity coefficient. It is the contribution of regional tourism revenue to regional GDP. It is also the ratio of gross regional tourism revenue to gross regional product (GDP); $\overline{\mathrm{TCC}}$ is the per capita tourism carbon carrying capacity, unit: $\mathrm{kg} /$ person.

\subsection{Net Carbon Footprint Model}

Net carbon footprint is a concept which used to measure the carbon emissions in the region and determine whether it is a restraining or promoting state to climate warming. If the calculation result is greater than 0 , it means that the carbon emission is greater than the carbon sequestration of vegetation, and the carbon emission is in the state of promoting climate warming. If the result is less than 0 , it is the state of carbon sink, and the amount that vegetation can carry is greater than the amount produced by the city, which has a certain deterrent effect on climate warming. If this is equal to 0 , we're in a carbon equilibrium (Hisatlmi et al., 2000; Zhang \& Zhen, 2016). The calculation formula of net carbon footprint is (Dong et al., 2018):

$$
\mathrm{NCF}=\mathrm{TCF}-\mathrm{TCC}
$$

In the formula: $N C F$ is the net carbon footprint, unit: kt.

\section{Carbon Footprint Analysis of Tourism in Sichuan Province}

\subsection{Data Sources and Calculation Results}

In this study, some data were obtained from "the statistical yearbook of Sichuan province" from 2004 to 2018, including the number of tourists, foreign exchange, domestic tourism income and total tourism income. The GDP and forest area of each year come from the statistical bulletin of Sichuan province's national economic and social development.

According to Formula (1)-(6), the calculation results are shown in the following Table 1.

\subsection{Dynamic Change Analysis of Tourism Carbon Footprint}

The carbon footprint of China's tourism is calculated according to Formula (1). The results show that the total carbon footprint of China's tourism was 4.2759 
Table 1. Calculation results of tourism carbon footprint and carbon carrying capacity in Sichuan province from 2004 to 2018.

\begin{tabular}{|c|c|c|c|c|c|c|c|}
\hline year & $\begin{array}{l}\text { Carbon footprint } \\
\text { of inbound tourisn } \\
\text { (Ten thousand tons }\end{array}$ & $\begin{array}{l}\text { The carbon footprint } \\
\text { n of domestic tourism } \\
\text { (Ten thousand tons) }\end{array}$ & $\begin{array}{l}\text { Carbon footprint } \\
\text { of tourism (Ten } \\
\text { thousand tons) }\end{array}$ & $\begin{array}{l}\text { Tourism carbon } \\
\text { carrying capacity } \\
\text { (Ten thousand tons) }\end{array}$ & $\begin{array}{c}\text { Net carbon } \\
\text { footprint (Ten } \\
\text { thousand tons) }\end{array}$ & $\begin{array}{l}\text { Per capita carbon } \\
\text { footprint of tourism } \\
\quad(\mathrm{Kg} / \text { person })\end{array}$ & $\begin{array}{l}\text { Per capita tourism } \\
\text { carbon carrying } \\
\text { capacity (kg/person) }\end{array}$ \\
\hline 2004 & 18.07 & 409.52 & 427.59 & 1626.59 & -1199.00 & 37.11 & 141.17 \\
\hline 2005 & 19.69 & 535.95 & 555.64 & 1920.73 & -1365.09 & 41.87 & 144.74 \\
\hline 2006 & 24.93 & 738.79 & 763.72 & 2332.78 & -1569.06 & 45.67 & 139.51 \\
\hline 2007 & 31.78 & 1002.32 & 1034.10 & 2459.84 & -1425.74 & 55.18 & 131.26 \\
\hline 2008 & 13.40 & 1017.05 & 1030.45 & 1824.14 & -793.68 & 58.80 & 104.08 \\
\hline 2009 & 18.07 & 1332.65 & 1350.72 & 2203.00 & -852.27 & 61.44 & 100.20 \\
\hline 2010 & 21.81 & 1685.04 & 1706.85 & 2632.95 & -926.10 & 62.74 & 96.78 \\
\hline 2011 & 36.76 & 2295.97 & 2332.74 & 2769.90 & -437.17 & 66.34 & 78.77 \\
\hline 2012 & 49.85 & 3188.25 & 3238.10 & 3292.98 & -54.88 & 73.22 & 74.46 \\
\hline 2013 & 47.36 & 3826.62 & 3873.98 & 3561.39 & 312.59 & 78.72 & 72.37 \\
\hline 2014 & 53.59 & 4919.94 & 4973.53 & 4161.34 & 812.19 & 91.69 & 76.72 \\
\hline 2015 & 73.53 & 6190.55 & 6264.08 & 5045.44 & 1218.64 & 105.68 & 85.12 \\
\hline 2016 & 98.45 & 7160.83 & 7259.28 & 5904.10 & 1355.18 & 114.66 & 93.26 \\
\hline 2017 & 90.35 & 8161.85 & 8252.20 & 6200.97 & 2051.23 & 122.55 & 92.09 \\
\hline 2018 & 94.09 & 9411.86 & 9505.95 & 6389.67 & 3116.28 & 135.09 & 90.80 \\
\hline
\end{tabular}

million tons in 2004 and 95.0595 million tons in 2018. This increased by 20.2 times during the 15 years. The carbon footprint is basically on the rise. But the total carbon footprint in 2008 was smaller than in 2007 (Figure 1). The Wenchuan earthquake in 2008 may be one of the reasons. Apart from the epicenter of the quake, Wenchuan, many places in Sichuan province were affected, with houses collapsing and landscapes destroyed. As a result, the total number of tourists in Sichuan province in 2008 decreased by 12.1465 million compared with last year, and the total tourism revenue decreased by 12.579 billion yuan.

Compared with domestic tourism, inbound tourism in general has been more affected. The number of domestic tourists decreased in 2008, but has recovered to the level before the earthquake in 2009, and even surpassed before. The number of inbound tourists decreased by 1.095 million in 2008, but it did not recover to the pre-earthquake level until 2012 (Table 2). In addition, the number of inbound tourists dropped by 177,000 from 2.273 million in 2012 to 2.096 million in 2013. The city of Ya'an in Sichuan province was hit by a 7.0-magnitude earthquake in 2013. Ya'an, as a tourist city in Sichuan province, has reduced the number of tourists and tourism income and damaged natural resources due to the earthquake. On July 8, 2013, the whole Sichuan was hit by severe floods. The cause of the change cannot be separated from the natural disasters in Sichuan.

The per capita carbon footprint of tourists is calculated according to Formula (2). In the past 15 years, the proportion of domestic tourism in Sichuan province is far greater than that of inbound tourism. However, the per capita carbon footprint 


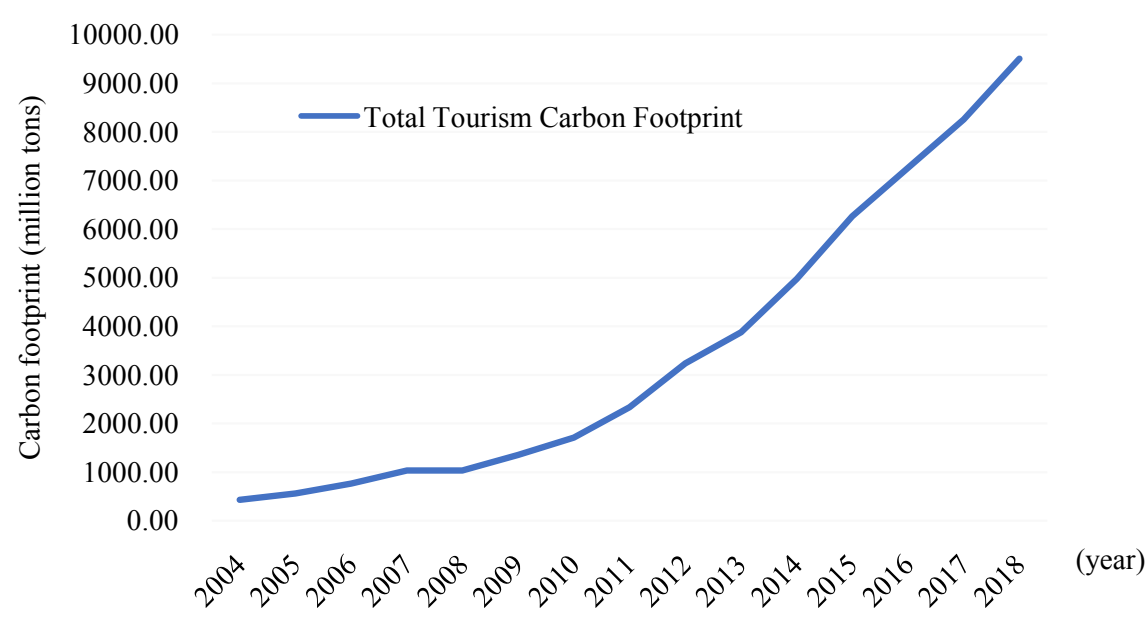

Figure 1. Variation trend of total carbon footprint of tourism in Sichuan Province from 2004 to 2018.

Table 2. Statistics on the number of tourists and forest area in Sichuan Province from 2004 to 2018.

\begin{tabular}{cccc}
\hline year & $\begin{array}{c}\text { Number of inbound tourists } \\
\text { (ten thousand) }\end{array}$ & $\begin{array}{c}\text { Number of domestic tourists } \\
\text { (ten thousand) }\end{array}$ & $\begin{array}{c}\text { Area of woods } \\
\text { (ten thousand ha) }\end{array}$ \\
\hline 2004 & 18.07 & 409.52 & 427.59 \\
2005 & 19.69 & 535.95 & 555.64 \\
2006 & 24.93 & 738.79 & 763.72 \\
2007 & 31.78 & 1002.32 & 1034.10 \\
2008 & 13.40 & 1017.05 & 1030.45 \\
2009 & 18.07 & 1332.65 & 1350.72 \\
2010 & 21.81 & 1685.04 & 1706.85 \\
2011 & 36.76 & 2295.97 & 2332.74 \\
2012 & 49.85 & 3188.25 & 3238.10 \\
2013 & 47.36 & 3826.62 & 3873.98 \\
2014 & 53.59 & 4919.94 & 4973.53 \\
2015 & 73.53 & 6190.55 & 6264.08 \\
2016 & 98.45 & 7160.83 & 7259.28 \\
2017 & 90.35 & 8161.85 & 8252.20 \\
2018 & 94.09 & 9411.86 & 9505.95 \\
\hline
\end{tabular}

of inbound tourism is much larger than that of domestic tourism (Figure 2). The difference between the two was about five times from the beginning to less than two times now. This shows that with the economic strength of Sichuan province enhanced, people's living standards improved. More and more people are traveling. The per capita tourism carbon footprint of Sichuan province is in line with the trend of domestic per capita tourism carbon footprint, which basically shows a slow rising trend (Figure 3 ). 


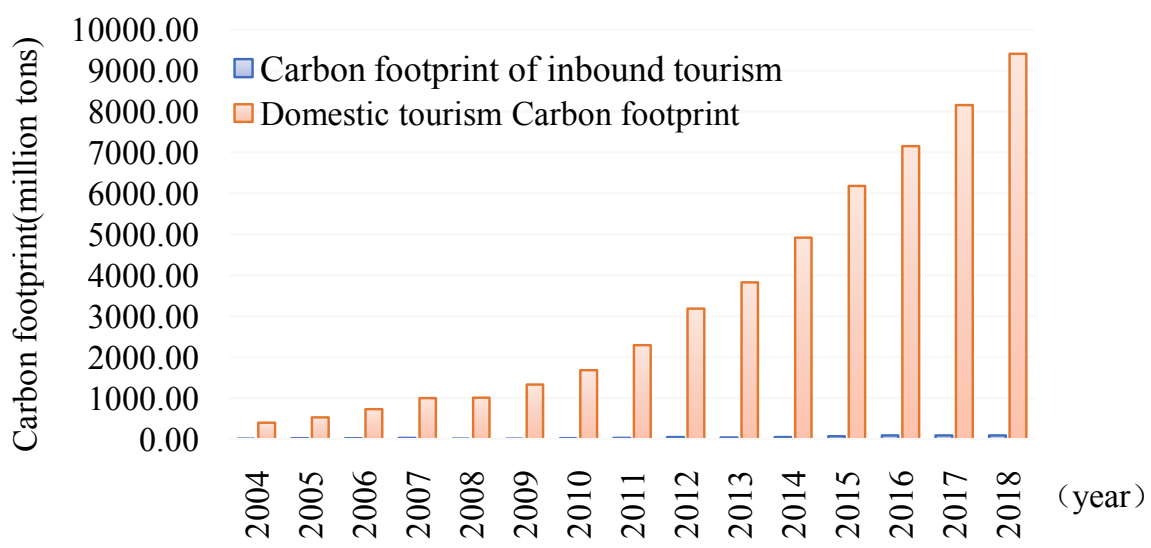

Figure 2. Variation trend of carbon footprint of inbound and domestic tourism in Sichuan Province from 2004 to 2018.

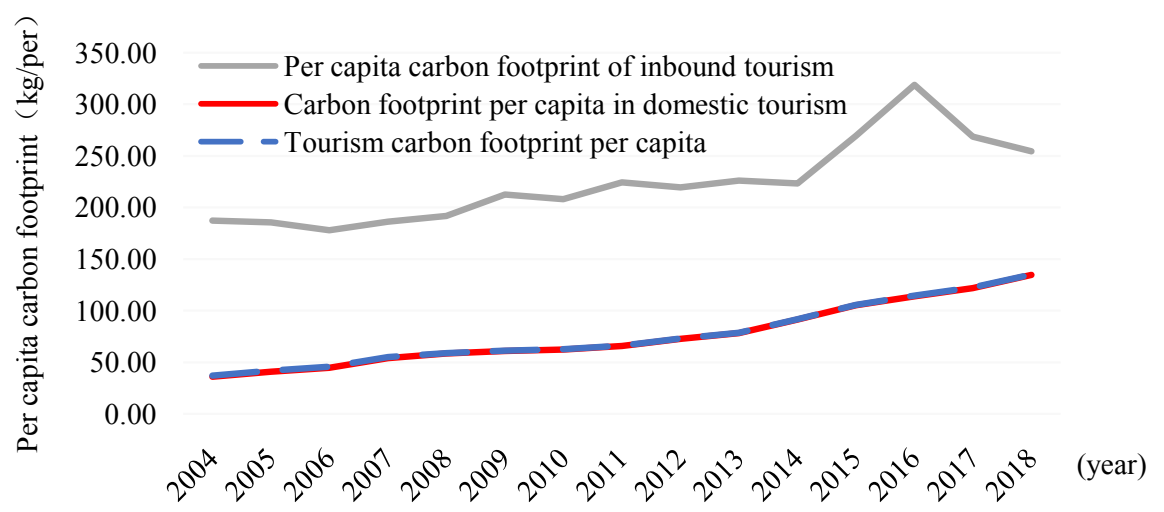

Figure 3. Change trend of per capita carbon footprint in Sichuan Province from 2003 to 2018.

\subsection{Dynamic Change Analysis of Tourism Carbon Capacity}

The tourism carbon carrying capacity of Sichuan province is still on the rise. The tourism carbon carrying capacity is calculated according to Formula (3)-(4). The results show that the tourism carbon carrying capacity increased from 16.2659 million tons in 2004 to 63.89967 million tons in 2018, which is a big increase. This is inseparable from the measures to develop tourism and protect ecological natural resources in Sichuan Province. But it still fell in 2008. In terms of social resources, the Wenchuan earthquake caused the performance of the tourism industry in Sichuan to decline, and the number of tourists and income decreased. In terms of natural resources, the forest resources in Sichuan were destroyed. The forest area fell from 89,023 hectares in 2007 to 87,443 hectares in 2008. It has been reduced by a total of 1580 hectares. This leads to a reduction in carbon sequestration, which in turn reduces carbon carrying capacity. The growth rate of tourism carbon carrying capacity is lower than that of the total tourism carbon footprint (Figure 4). Therefore, from 2004 to 2012, the tourism carbon carrying capacity of Sichuan province was larger than its carbon footprint. It shows a carbon surplus. From 2012 to 2018, the carbon carrying capacity is smaller 


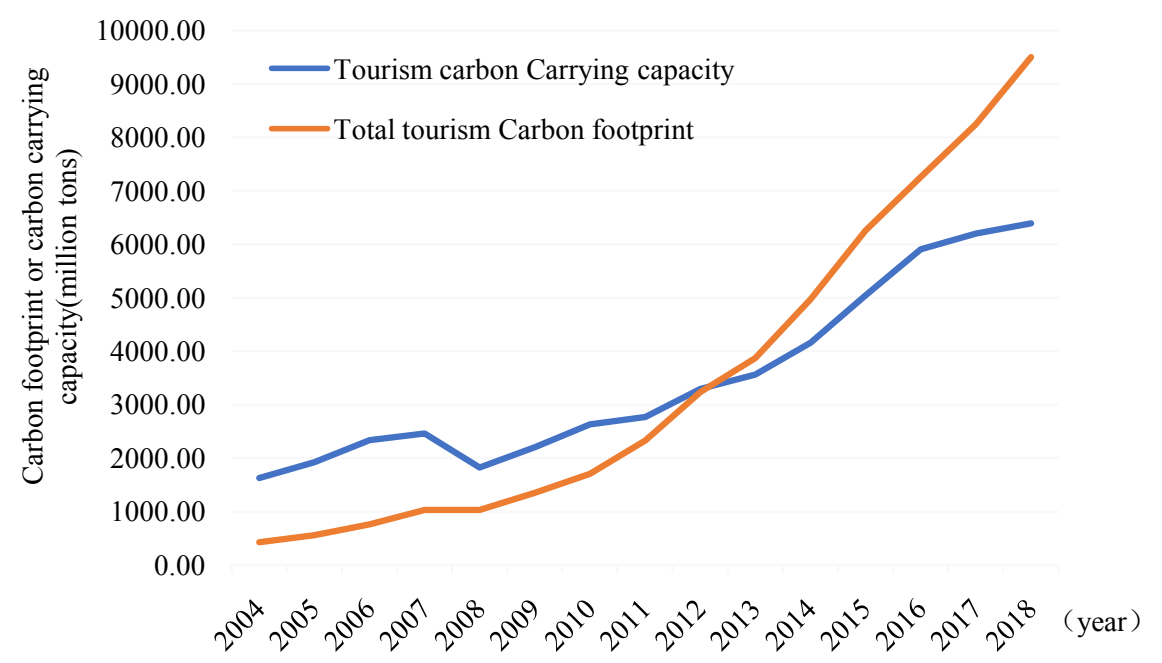

Figure 4. Variation trend of carbon footprint and carbon carrying capacity in Sichuan province from 2004 to 2018.

than the carbon footprint. It shows the state of carbon deficit. This phenomenon contributed to the rise in temperature.

The per capita carbon footprint of tourism in Sichuan province increased by $264 \%$ from $37.11 \mathrm{~kg} /$ person to $135.09 \mathrm{~kg} /$ person. Although the number of tourists is on the rise, the growth rate is smaller than the growth rate of the total carbon footprint of tourism. Therefore, the per capita tourism carbon footprint is increasing (Figure 5). On the contrary, the per capita tourism carbon carrying capacity basically showed a downward trend from 2004 to 2013, from 141.17 $\mathrm{kg} /$ person to $72.37 \mathrm{~kg} /$ person, which may be related to the change of forest area in Sichuan province in recent years. In 2013, there was not only an earthquake in Sichuan, but also a huge flood, which caused extreme damage to forest resources, resulting in a decline of 5,950 hectares of forest area in 2013.

\subsection{Dynamic Analysis of Net Carbon Footprint}

The net carbon footprint is calculated by Formula (6). The results show that the net carbon footprint of Sichuan province is negative from 2004 to 2012, and it is in the state of carbon surplus (Figure 6). The total precipitation in 2006 was less than that in previous years. Sichuan has been hit by a rare heat wave and a severe drought. Vegetation was destroyed and tourism in Sichuan was affected. It serves as a turning point, as the net carbon footprint increases over the next two years and becomes increasingly close to the carbon deficit. From 2013 to 2018, the carbon footprint is far greater than the carbon carrying capacity. The net carbon footprint increased by 7.97 times from 3.1259 million tons to 31.1628 million tons. It's been a carbon deficit for a few years now, and it's growing very fast. This has caused great pressure on the tourism ecological environment.

\section{Conclusion}

Based on the construction of carbon footprint, carbon carrying capacity and net 


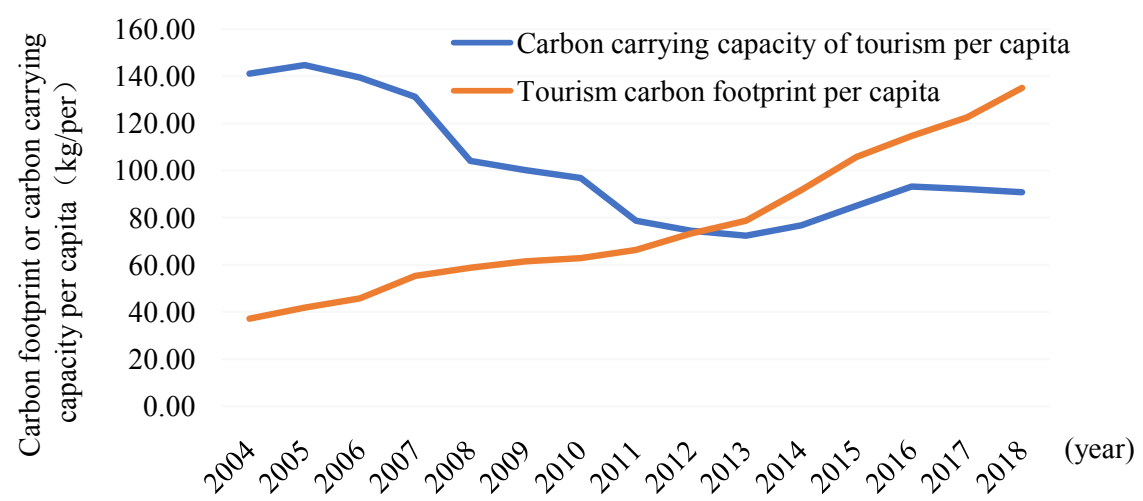

Figure 5. Variation trend of per capita carbon footprint and carbon carrying capacity in Sichuan province from 2004 to 2018.

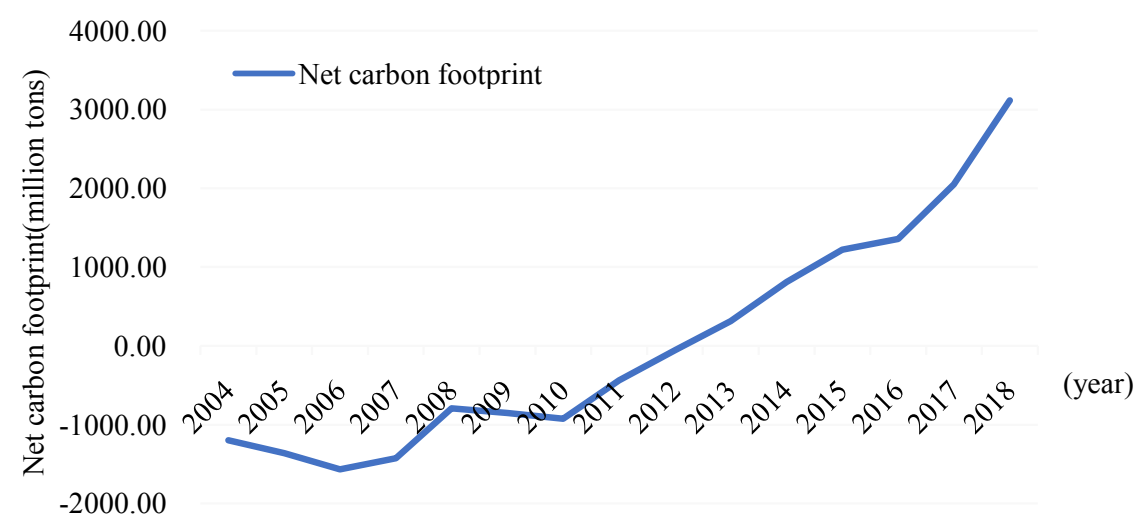

Figure 6. Change trend of Sichuan Province's net carbon footprint from 2004 to 2018.

carbon footprint model, this paper analyzes the trend change of tourism carbon emission in Sichuan province from 2004 to 2018. The following conclusions are drawn:

The tourism carbon footprint of Sichuan province increased by 90,783,600 tons in the past 15 years, which is a big increase. This shows that people's living standard is improving and they attach more and more importance to the quality of life. Therefore, the number of tourists is increasing gradually, and the growth rate of domestic tourism carbon footprint is much higher than that of inbound tourism carbon footprint.

Sichuan province has suffered many natural disasters during the past 15 years, such as the devastating drought in 2006, the Wenchuan earthquake in 2008, the Ya'an earthquake in 2013 and the devastating floods. All these have an impact on the number of tourists and natural resources in Sichuan. So, the tourism carbon carrying capacity fluctuates greatly. However, due to the special emphasis on forestry construction, the carbon carrying capacity is still on the rise, but the growth rate is lower than the growth rate of carbon footprint. According to the research results, Sichuan province had a carbon surplus before 2012. Tourism carbon carrying capacity is larger than carbon footprint, and ecological pressure is relatively small. It has been in a carbon deficit since 2012. The main reason is 
that tourism's carbon footprint is growing too fast. In order to formulate the carbon emission reduction measures for tourism, we need to start from the carbon footprint (Table 2).

In order to reduce carbon emissions from tourism, it is a top priority to enhance tourists' awareness of emission reduction. The first thing to consider is the tourists' accommodation, food and shopping. To encourage green travel, take public transport as far as possible, and do not drive a car. This will not only ease traffic congestion, but also reduce exhaust emissions. Pay attention to rational consumption and green consumption when playing, and try to develop green eco-tourism. At the same time, the government should reasonably plan the tourist sites and routes. More efforts should be made to build forest land, increase the amount of carbon sequestration, and work with citizens to reduce carbon emissions from tourism.

In this paper, the carbon footprint and carbon carrying capacity of tourism in the past 15 years have been studied, and the current situation of Sichuan province has been analyzed. But there are many shortcomings. It lacks a lot of more detailed analysis, and fails to analyze the behaviors of tourists such as food, accommodation, transportation and shopping, which is not deep enough. In the follow-up study, the spatial pattern of tourism carbon footprint in Sichuan province may be analyzed or investigated from the aspects of tourism traffic structure and energy structure.

\section{Conflicts of Interest}

The authors declare no conflicts of interest regarding the publication of this paper.

\section{References}

Becken, S., Simmons, D. G., \& Frampton, C. (2003). Energy Use Associated with Different Travel Choices. Tourism Management, 24, 267-277. https://doi.org/10.1016/S0261-5177(02)00066-3

Cao, H., Yan, S. J., Lei, D. J., Lin, M., \& Zhang, L. L. (2014). Evaluation of Tourism Carbon Footprint in Fujian Province in Recent Ten Years. Journal of Safety and Environment, 14, 306-311.

Dong, H. Y., Liu, Q. P., Zhou, L., \& Yu, Z. P. (2018). Dynamic Comparative Analysis of Carbon Footprint and Carbon Bearing Capacity of Tourism in Jiangsu Province. Ecological Economy, 34, 183-187.

Gössling, S., \& Michael, H. C. (2008). Swedish Tourism and Climate Change Mitigation: An Emerging Conflict? Scandinavian Journal of Hospitality and Tourism, 8, 141-158. https://doi.org/10.1080/15022250802079882

Hisatlmi, H., Yoshinori, Y., Yoshihito, S., \& Tetsuya, H. (2000). Variations in Nitrogen Uptake and Nitrate-Nitrogen Concentration among Sorghum Groups. Soil Science and Plant Nutrition, 46, 97-104. https://doi.org/10.1080/00380768.2000.10408766

Jiang, D. H., \& Jin, X. (2015). Research on Tourism Carbon Footprint of Shandong Province Based on Terminal Consumption. China Population, Resources and Environment, $25,450-453$. 
Liao, Q. D., \& Gong, F. H. (2014). Dynamic Analysis of Carbon Footprint and Carbon Bearing Capacity in Xiamen City. Fujian Architecture and Construction, 11, 1-3.

Lu, H. (2018). Research Progress and Prospect of Tourism Carbon Footprint Measurement. Tourism Research, 10, 75-83.

Peng, W. F., Zhou, J. M., Xu, X. L., Luo, H. L., Zhao, J. F., \& Yang, C. J. (2016). Effect of Land Use Changes on the Temporal and Spatial Patterns of Carbon Emissions and Carbon Footprints in the Sichuan Province of Western China, from 1990 to 2010. Acta Ecologica Sinica, 36, 7244-7259. https://doi.org/10.5846/stxb201506111188

Scott, D., Amelung, B., Becken, S., Ceron, J. P., Dubois, G., Gössling, S., Stefan, L. U., Peeters, P., \& Simpson, M. (2008). Climate Change and Tourism: Responding to Global Challenges. Madrid: World Tourism Organization.

Wang, K., Shao, H. Q., Zhou, T. T., \& Liu, H. L. (2017). Analysis of Impact Factors of CO 2 Emissions from Tourism in China Based on STIRPAT Model. Acta Scientiae Circumstantiae, 37, 1185-1192.

Wang, L. G., Liao, W. M., Huang, M., \& Deng, R. G. (2011). Calculation of Tourism Carbon Footprint on Final Consumption: A Case of Jiangxi Province. Ecological Economy, No. 5, 121-124+168.

Weidema, B. P., Thrane, M., Christensen, P., Schmidt, J., \& Lokke, S. (2008). Carbon Footprint: A Catalyst for Life Cycle Assessment? Journal of Industrial Ecology, 12, 3-6. https://doi.org/10.1111/j.1530-9290.2008.00005.x

Wu, Z. (2015). Measurement of Carbon Footprint of Regional Tourism: A Case Study of Nanyue Scenic Spot. Systems Engineering, 33, 107-114.

Yao, Z. G., \& Chen, T. (2016). An Empirical Study on Tourism Carbon Emissions Based on Carbon Footprint Model: A Case Study of Hainan Province. Economic Management, 38, 151-159.

Zhang, X. P., \& Zhen, G. Z. (2016). Dynamics of Carbon Footprint and Carbon Carrying Capacity of Shanxi Province. Journal of Shanxi Agricultural University (Natural Science Edition), 36, 128-132.

Zhao, X. G., Ma, C. H., Xiao, L., \& Hu, P. F. (2013a). Dynamic Study on Carbon Footprint and Carbon Bearing Capacity in Beijing. Journal of Arid Land Resources and Environment, 27, 8-12.

Zhao, X. G., Ma, C. H., Xiao, L., \& Ji, F. R. (2013b). Study on Spatio-Temporal Variation of Carbon Footprint in Shaanxi Province. Scientia Geographica Sinica, 33, 1537-1542.

Zhao, X. R., Liu, X. M., \& Cong, J. H. (2014). Research Progress on Low-Carbon Tourism and Its Future Prospect. Resource Development \& Market, 30, 239-243. 